\title{
EDUCAÇÃO E SOCIEDADE: UM OLHAR SOBRE A OBRA PEDAGÓGICA DE DURKHEIM
}

\author{
Afonso Welliton de Sousa NASCIMENTO ${ }^{1}$ \\ Campus Universitário de Abaetetuba/UFPA \\ afonsosn@ufpa.br \\ Edinéa Bandeira RIBEIRO \\ SEMEC \\ edineabr@ig.com.br
}

Resumo: O artigo reflete sobre o pensamento pedagógico de Durkheim. Inicialmente faz uma incursão no contexto da formação da sociedade moderna destacando o caráter utópico da construção do conhecimento humano referenciandose no pensamento filosófico e educacional de Kant e Bacon, como construtores da ilustração científica do iluminismo. A seguir, caminha na influência da dupla revolução europeia, que determinou aspectos importantes no pensamento dos autores subsequentes do Século XIX. Reflete o pensamento de Comte e sua fundamentação teórica às concepções durkheimianas, centrando no caráter evolucionista e positivista de sua filosofia. Por fim, analisa os conceitos do pensamento funcionalista de Durkheim, seus aspectos sociológicos e educacionais e sua influência nas teorias educacionais atuais.

Palavras-chave: Modernidade. Iluminismo. Positivismo. Funcionalismo.

Abstract: The article reflects on the pedagogical thinking of Durkheim. Initially, a foray into the context of the formation of modern society highlighting the utopian character of the construction of human knowledge referencing the philosophical and educational thought of Kant and Bacon, as builders of scientific illustration of the Enlightenment. Then walks in the dual influence of European revolution, which led to important aspects in the thinking of subsequent authors of the XIX century. Reflects the thinking of Comte and its theoretical foundation to Durkheimian concepts, focusing on evolutionary and positivist character of his philosophy. Finally, it analyzes the concepts of functionalist thought of Durkheim, sociological and educational aspects and its influence on current educational theories.

Keywords: Modernity. Enlighttenment. Positivism. Functionalism.

\footnotetext{
${ }^{1}$ Doutorando em Educação pela Universidade Federal do Ceará/UFC.

${ }^{2}$ Mestre em Educação pela Universidade Federal do Pará/UFPA.
} 


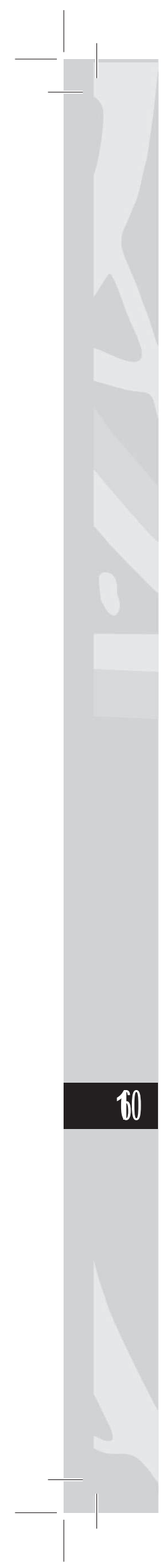

\section{Introdução}

Os efeitos provocados pela dupla revolução europeia - a Industrial e a Francesa - trouxeram consequências econômicas e sociais profundas: o aparecimento da indústria e com ela a hegemonia burguesa na modernidade capitalista, o surgimento do trabalho assalariado e com ele o proletariado, assim como o fenômeno da urbanização desenfreada. Tais mudanças irão exigir dos pensadores formas científicas de entender a realidade presente, trazendo para além do universo filosófico, a perspectiva da ciência na compreensão do universo da economia e da sociedade.

$\mathrm{Na}$ verdade, davam-se efetivamente os olhares racionais traduzidos pelos iluministas, de um lado, a revolução científica, de outro, estado nacional firmava-se com a ideia do contrato social. Os princípios liberais de sociedade e indivíduo constituíam-se envolvidos no universo da hegemonia burguesa, mesmo que em si fossem contraditórios.

A utopia da modernidade e seus pensadores passavam pela formação do indivíduo culto e ilustrado, científico e racional e a educação como elemento componente deste projeto de sociedade do Século XVIII. Esta mesma mentalidade continuaria presente no pensamento do Século XIX, porém profundamente crítico aos desajustes sociais existentes com as consequências geradas pelo processo urbanização desencadeadas na sociedade europeia.

Cabia-lhes então, o papel essencial, de reestruturar a ordem social gerada com o início da modernidade, porém sem prescindir dos princípios que fundamentavam a racionalidade antropocêntrica do mundo ocidental. Contudo, acrescentariam novos elementos: ao lado do sujeito cidadão, incorporariam outra concepção centrada principalmente na racionalidade do mundo da economia e da divisão científica e técnica do trabalho.

É esse contexto de restauração e contradição que dará sustentabilidade ao pensamento sociológico durkheimiano. As necessidades prementes de compreensão dos fenômenos sociais em 
voga servirão de elementos constitutivos de interpretação de sua concepção.

Seu funcionalismo definirá de forma organizada o papel da Sociologia como ciência na compreensão da sociedade e da educação como formadora do espírito racional da solidariedade orgânica presente na urbanidade do século XIX, no qual a nova ordem social científica se daria pelo fundamento solidário do altruísmo definido pela divisão social do trabalho, ou através da dimensão da solidariedade orgânica efetivada na urbanidade própria da dinâmica moderna e, consequentemente, da educação.

O artigo, então, estará em consonância com essa dinâmica acima exposta. Será dividido em duas secções, na primeira, partiremos do contexto que dá sustentabilidade a sua teoria: o caráter racional, urbano e industrial que funda o ambiente no século XIX e dimensiona o papel da educação.

E na segunda, o construto de sua concepção, apontados em sua compreensão evolucionista do sistema social. Caracterizados nos conceitos de fato social, solidariedade, altruísmo e divisão social do trabalho, conceitos que esses, que incidem sobre sua análise do papel da educação no mundo moderno.

Além disso, à guisa de conclusão, retomaremos essa análise a partir dos conceitos de evolução, equilíbrio, integração e estabilidade, para compreender como o olhar da teoria funcionalista de educação exerce influência nas interpretações sistêmicas da educação nos dias atuais.

\section{Formação da sociedade moderna: da utopia de Kant e Bacon ao positivismo de Comte - os fundamentos das concepções durkheimianas}

A realidade que dá sustentabilidade ao pensamento sociológico e educacional de Durkheim remonta períodos anteriores, que se estruturam a partir da constituição do que em voga conheceremos de modernidade. A transitoriedade do mundo medieval traz consigo 


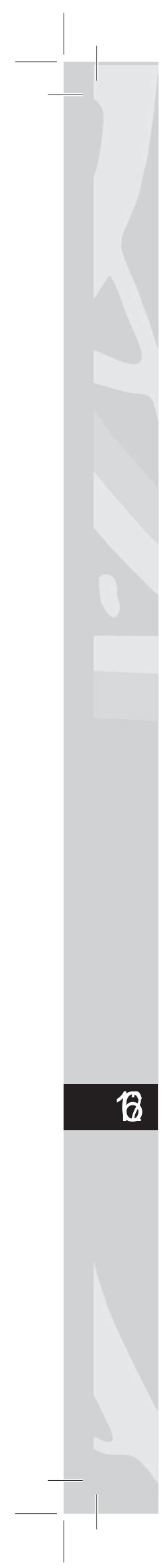

elementos outros que põem em destaque uma nova dimensão humana, de cultura, economia e sociedade.

$\mathrm{Na}$ verdade, compreender este momento nos faz desvelar o construto efetivo do saber no mundo ocidental moderno. $\mathrm{Na}$ própria mentalidade de formação de um novo processo civilizatório que se transformou nos Séculos XVI, XVII e XVIII e passaria pela superação do estado de menoridade social - característico da idade média cristã - e caminharia a uma nova realidade moderna capitalista centrada na autonomia do sujeito liberal, autônomo, racional e livre: o cidadão.

Se isto já se expressava de forma contundente nos princípios que traduziam os acontecimentos em curso, norteavam-se principalmente nos pensamentos filosóficos de pensadores como Descartes, Hegel e outros. E tornar-se-ia mais contundente no pensamento filosóficopolítico Kantiano, de superação da menoridade social e do surgimento da racionalidade própria da modernidade, com a construção da consciência social.

Segundo ele, inaugura-se um novo tempo - o tempo do esclarecimento - no qual somente o homem é capaz de superá-lo, depois de permitido que isso acontecesse somente ele pode superar a sua menoridade social; como ele diria:

\begin{abstract}
É difícil, portanto, para um homem em particular desvencilhar-se da menoridade que para ele se tornou quase uma natureza. Chegou mesmo criar amor a ela, sendo por ora realmente incapaz de utilizar seu próprio entendimento, porque nunca o deixaram fazer a tentativa de assim proceder. Preceitos e fórmulas, estes instrumentos mecânicos do uso racional, ou antes, do abuso, de seus dons naturais, são grilhões de uma perpétua menoridade. Quem deles se livrasse só seria capaz de dar um salto inseguro mesmo sobre o mais estreito fosso, porque não está habituado a este movimento livre. (KANT, 1985. p. 17)
\end{abstract}

Assim, ele afirma que ao encontrarem esse esclarecimento o caminho é sem volta e, portanto, inevitável: 
Que porém um público se esclareça - aufklàre - a si mesmo é perfeitamente possivel; mais que isso, se the for dada a liberdade é quase inevitável. Pois encontrar-se-ão sempre alguns indivíduos capazes de pensamento próprio, até entre os tutores estabelecidos da grande massa, que, depois de terem sacudido de si mesmo o jugo da menoridade, espalharão em redor de si o espírito de uma avaliação racional do próprio valor $e$ da vocação de cada homem em pensar por si mesmo. (idem, 1985, p. 18)

Essa concepção que fundamenta seu pensamento social dá origem ao conceito de liberdade assumida pelo iluminismo. E traz também consigo a necessidade de uma nova dimensão educacional. Colocando na educação o papel de instrumento de construção da consciência social e de formação da racionalidade moderna. Para ele, somente o ser humano é capaz de superar o seu estado de menoridade social, pois diferentemente de outros seres existentes na terra é o único que não nasce pronto e acabado; e que precisa de cuidados, ou seja, que se constitui como infante.

$\mathrm{Na}$ verdade, Kant acaba por um lado de instituir na história de vida humana o conceito de infância, da necessidade efetiva de cuidado; e de outro fundar o caráter civilizatório da humanidade, por meio da educação. Segundo ele, é através da disciplina e da instrução que o ser humano irá superar o seu estado de selvageria e entrar no mundo do sujeito educado e racional, ou seja, com uma formação centrada na disciplina capaz de refrear o seu instinto de animalidade, e da formação moral pela instrução, a construção da racionalidade do sujeito civilizado. Como ele afirma,

O homem é a única criatura que precisa ser educada. Por educação entende-se o cuidado com a infância (a conservação, o trato), a disciplina e a instrução com a formação. Consequentemente, o homem é infante educando e discípulo. (KANT, 1990, p. 15)

E acrescenta:

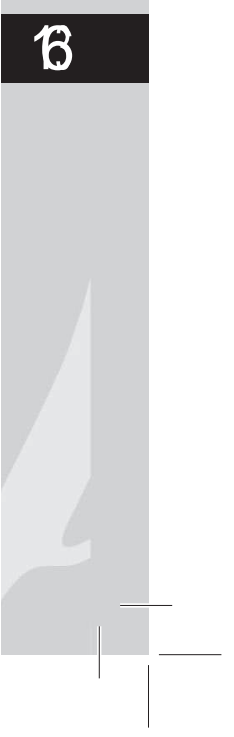




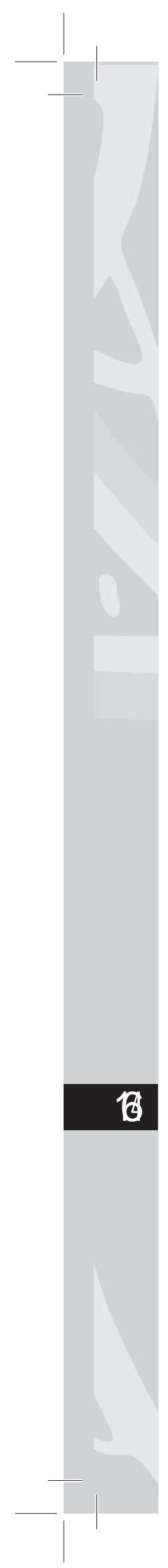

O homem não pode se tornar um verdadeiro homem senão pela educação. Ele é aquilo que a educação dele faz. Note-se que ele só pode receber esta educação de outros homens, os quais a recebem igualmente de outros. Portanto, a falta de disciplina e de instrução em certos homens os torna mestres muito ruins de seus educandos. (idem, 1990, p. 16)

Em Kant, portanto, deu-se o início da formação da utopia moderna. Do que iria fundamentar fortemente a perspectiva de formação traduzida no pensamento iluminista, ou seja, do indivíduo ilustrado e consciente, o ser autônomo racional e livre.

Assim como em Kant, não iria diferir no pensamento de Bacon (1980). Agora não somente a autonomia do sujeito como indivíduo, mas na formação para a materialidade do mundo científico, i. e, voltado ao desenvolvimento da ciência e do progresso Industrial.

Segundo ele em o Novum Organum (idem, 1980), a superação dos ídolos, daquilo que dificultava o progresso humano, se resolveria com a formação de um novo instrumento, o método racional e científico, próprio das artes mecânicas, que daria um novo fundamento epistemológico à existência humana.

Mesmo que em Bacon não se encontre uma descoberta relevante, ele introduz no conhecimento ocidental uma nova atitude racional e metódica de desenvolvimento do saber e, ao mesmo tempo coloca no conhecimento humano, a necessidade premente de buscar por si mesmo o saber científico, e do mesmo modo apropriar-se da natureza. Inaugura-se então com ele a mentalidade do que conheceremos de progresso científico e/ou em sua origem, a linguagem da ciência e da tecnologia.

Com isto, fundam-se com Kant e Bacon, os princípios da educação e da dinâmica utópica do projeto racional e científico da modernidade, completa-se a prospecção do caminho que deveria trilhar a humanidade, ou seja, superando sua menoridade social/ religiosa e penetrando na esfera da racionalidade científica e social, que então construiria o projeto de felicidade edificadora da humanidade posta no mundo da civilização moderna. 
Da mesma forma, posiciona a necessidade do conhecimento científico como fundamento essencial do saber e do estudo humano, de estabelecer no indivíduo a superação religiosa e, consequentemente, o fundamentar-se por ações racionais centradas na ciência. Além disso, por entre os discursos, o compromisso social e a responsabilidade do estado com a formação desse novo sujeito, pautando-se o caráter laico do conhecimento e da invenção, do lócus próprio da formação moderna em substituição a igreja, com a fundante criação da escola e do ensino laico.

Esse contexto influenciará profundamente o seculo XIX, embora em um ambiente cercado por críticas às estruturas sociais herdadas, não significará um rompimento com os fundamentos utópicos modernos. Cabia aos pensadores cumprir o papel essencial, de reorganizar a ordem social, porém sem prescindir dos princípios que fundamentavam a racionalidade antropocêntrica do mundo ocidental. Entretanto deveriam acrescentar outras perspectivas, em conjunto com a dimensão do sujeito cidadão, incorporariam a concepção centrada principalmente na racionalidade do mundo da economia e da divisão científica e técnica do trabalho.

Essa perspectiva encontraria ressonância nas correntes de pensamento que fundamentariam a modernidade e sua concepção de educação no século XIX, principalmente, no pensamento Positivista de Auguste Comte e nas obras sociológicas e educacionais de Durkheim.

Em Auguste Comte, o caráter do sujeito autônomo, racional e livre de Kant encontraria sua realização em uma sociedade racional e moralmente científica; a superação da mentalidade religioso-metafísica de mundo, própria do processo histórico de evolução da espécie humana descobriria seu destino definitivo em uma ordem social positiva construída e fundamentada na ciência. Para ele, a organização moral do mundo moderno pautava-se no altruísmo científico elevado pela cátedra do conhecimento, onde o cientista assumiria o sacerdócio efetivo do todo social moral da modernidade.

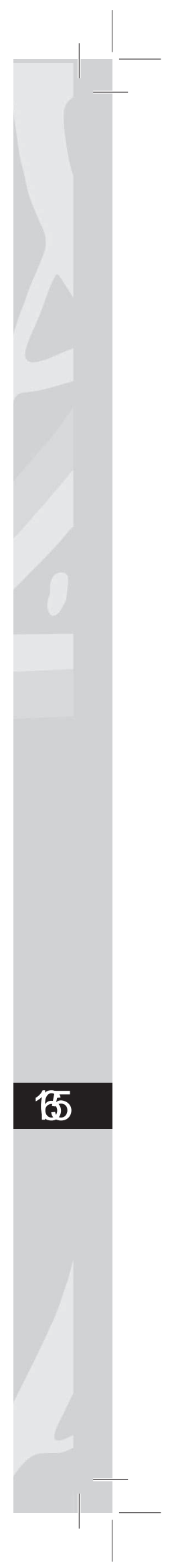


Esta concepção de mundo e sociedade daria na teoria de Comte os fundamentos e o papel da educação no século XIX. Retomando os princípios racionais e científicos da evolução do conhecimento desde a antiguidade clássica, passando pela metafísica grega e medieval, bem como, pela evolução científica de Galileu e Bacon; funda o que ele vai chamar do curso de filosofia positiva, onde aprofunda desde o estudo do conhecimento mais abstrato a astronomia, passando pelas ciências naturais até chegar ao conhecimento racional da sociedade.

$\mathrm{Na}$ verdade Comte estrutura de forma curricular a educação e o método de ensino a ser apropriado pela escola moderna. Ele fundamenta seu curso, explicando o caráter da abordagem a ser assumida pela filosofia positiva. Em linguagem própria, explica:

Como ela se distingue principalmente por uma contínua preponderância, há um tempo lógica $e$ científica, do ponto de vista histórico ou social, devo em primeiro lugar, para melhor caracterizá-la, lembrar de modo sumário a grande lei que estabeleci, em meu sistema de filosofia positiva, sobre a evolução total da Humanidade, lei à qual por outro lado nossos estudos astronômicos deverão em seguida recorrer com frequência. (COMTE, 1995, p. 22)

E constitui a hierarquia das ciências:

Chega-se assim gradualmente a descobrir a invariável hierarquia, a um tempo histórica e dogmática, igualmente científica e lógica, das seis ciências fundamentais, a matemática, a astronomia, a física, a química, a biologia e a sociologia, das quais a primeira constitui necessariamente o ponto de partida exclusivo e a última o fim único e essencial de toda a filosofia positiva, considerada doravante como formando, por sua natureza, um sistema verdadeiramente indivisivel, onde toda decomposição é radicalmente artificial, sem ser alias, de nenhum modo, arbitrária, relacionandose tudo isso enfim a humanidade, única concepção plenamente Universal (idem, 1995, p. 23) 
Seguindo este mesmo fio condutor, o funcionalismo de Durkheim definirá de forma organizada o papel da Sociologia como ciência na compreensão da sociedade e da educação como formadora do espírito racional da solidariedade orgânica presente na urbanidade do século XIX, no qual a nova ordem social científica se daria pelo fundamento solidário do altruísmo definido pela divisão social do trabalho. Através da dimensão da solidariedade orgânica efetivada na urbanidade própria da dinâmica moderna e, consequentemente, da educação.

É na formação da divisão técnico-científica que a educação, através da ciência, constituirá a formação ética e moral do espírito da humanidade. Tomando por base a metáfora da teoria do espelho no qual a imagem da sociedade e/ou da educação deveria refletir no indivíduo da mesma forma que na sociedade.

\section{A educação na teoria funcionalista de Durkheim}

Assim penetrar na obra pedagógica de Durkheim, significa de um lado, entender que seus escritos se coadunam com essa mentalidade acima descrita e, de outro, que seu pensamento educacional é fruto de sua elaboração sociológica.

Neste sentido, o primeiro conceito básico que o identifica com o pensamento comtiano, e dá as primeiras noções de sociedade é o caráter sistêmico e evolucionista de sua teoria, de observá-la como um sistema funcional biológico, característico do corpo humano, tanto em sua estrutura estática quanto em sua função dinâmica. Esses aspectos que se manifestam na dimensão humana expressam-se em sua teoria da sociedade e refletem na sua visão de educação.

Esse olhar evolucionista toma corpo em sua concepção de história, para ele os sistemas e/ou as instituições sociais são realidades contínuas que se acumulam e permitem mudanças significativas, ou que justificam rompimentos com as construções anteriores. Além disso, são realidades que se estruturam a partir de bases econômicas 
próprias, ou que se organizam em contextos que se elevam e dão sentidos as suas instituições, possibilitando acúmulo de experiências e movimentos que geram transformações.

Esse modo de interpretar a sociedade aprofunda-se em sua obra sobre as origens dos sistemas modernos de ensino, para ele a educação não é um simples apêndice social, mas ela expressa a temporalidade de um povo, sua evolução histórica e o desenvolvimento econômico cultural de suas instituições. Em sua linguagem:

\begin{abstract}
Ao invés de nos perguntarmos primeiro em que consiste o ideal contemporâneo, devemos transportarmo-nos ao outro extremo da história; o ideal pedagógico mais longínquo, o primeiro a ser elaborado por nossas sociedades europeias, é o que devemos procurar alcançar, observando, descrevendo e explicando tanto quanto for possivel. A seguir, acompanharemos passo a passo a série das variaçôes pelas quais passou sucessivamente à medida que as próprias sociedades se transformaram, até finalmente, chegarmos aos tempos contemporâneos. (DURKHEIM, 1995, p. 20)
\end{abstract}

Da mesma forma que enfatiza esse aspecto dinâmico, ele incorpora a mentalidade da estática e do equilíbrio das instituições em seu processo evolutivo. Há um contínuo que se organiza, mas que permanece estruturado em sua evolução histórica permitindo movimento do todo orgânico social. Em sua elaboração o hoje é continuação equilibrada das formações institucionais anteriores. Assim mais adiante ele afirma:

Os homens do Renascimento estavam convencidos de que nada deveria ficar da escolástica; $e$, na verdade, sob essa violenta força, não sobrou muita coisa. Deveremos perguntar-nos se dessa atitude revolucionária não resultou alguma grave lacuna no ideal pedagógico que nos foi transmitido pelos homens do Renascimento. Assim, a história nos permitirá não só afirmar nossos princípios, mas também descobrir, às vezes, aqueles de nossos predecessores dos quais devemos tomar 
consciência, pois somos seus herdeiros. (Idem, 1995, p. 23)

Essa mentalidade, então trará em sua compreensão outros conceitos sociológicos fundamentais na interpretação da educação francesa de seu tempo, de tomá-la como formadora do ideal de sociedade de um contexto determinado, marcado essencialmente por aspectos morais e formativos. Na verdade ele se pergunta qual deva ser a educação ideal, porém afirma que não há esse ideal, pois buscálo simplesmente na história seria cair em uma abstração que negaria sua efetividade no concreto. Isto significaria dizer que admitiríamos de modo implícito que um sistema educativo não é, por si mesmo, nem um pouco real.

Assim, ele vai afirmar a ideia da educação como fato social coletivo e coercitivo da sociedade sobre o indivíduo, o qual é uma premissa das gerações passadas sobre o presente, definindo-a como uma condição institucional posta no contexto em que está inserida. $\mathrm{Na}$ sua perspectiva, expressa a mentalidade mais ampla de educação e seu caráter exterior e inculcador dos valores sociais:

De fato, é a sociedade que nos faz sair de nós mesmos, que nos obriga a considerar interesses diferentes dos nossos, que nos ensinou a dominar os nossos ímpetos e instintos, a sujeitá-los a leis, anos reprimir, privar, sacrificar, subordinar os nossos fins pessoais a fins mais elevados. Foi à sociedade que instituiu nas nossas consciências todo o sistema de representação que alimenta em nós a ideia e o sentimento da regra e da disciplina tanto internas quanto externas. Foi assim que adquirimos o poder de resistir a nós mesmos, ou seja, o domínio sobre nossas vontades, um dos traços marcantes da fisionomia humana desenvolvido à medida que nos tornamos mais plenamente humano. (DURKHEIM, 2011, p. 59)

Esta interpretação nos leva à formação efetiva do sujeito racional e livre interposto à condição da sociedade e seus valores. A 
educação assume na sua sociologia um aspecto essencial na dinâmica da sociedade moderna, a inculcação dos princípios morais e éticos que definirão não só o conceito de ser humano, mas a ética determinada pela ação científica. Esse espírito racional encontrará guarida no conceito de solidariedade orgânica presente na urbanidade, em que a nova ordem social científica se daria pelo fundamento solidário do altruísmo definido pela divisão social do trabalho.

A educação teria, portanto, a dupla função de estabelecer, por um lado, valores morais circunscritos ao sentido leigo e racional da sociedade, e de outro estabelecer a divisão técnica e científica que estaria inerente a complexificação social trazida pela ciência. Neste sentido ela seria una e múltipla, capaz de formar o cidadão e de estabelecer a diversidade na sociedade. Assim ele afirma:

\begin{abstract}
O resultado destes fatos é: que cada sociedade elabora um certo ideal do homem, ou seja, daquilo que ele deve ser tanto do ponto de vista intelectual quanto físico $e$ moral; que este ideal é, em certa medida, o mesmo para todos os cidadãos; que a partir de certo ponto ele se diferencia de acordo com os meios singulares que toda sociedade compreende em seu seio. É este ideal, único e diverso ao mesmo tempo, que é o pólo da educação. (Idem, 2011, p.52)
\end{abstract}

$\mathrm{Na}$ verdade ele vai definir a natureza e a função da educação na sociedade com a seguinte máxima:

A educação é a ação exercida pelas gerações adultas sobre aquelas que ainda não estão maturas para a vida social. Ela tem como objetivo suscitar e desenvolver na criança um certo número de estados físicos, intelectuais e morais exigidos tanto pelo conjunto da sociedade política quanto pelo meio específico ao qual ela está destinada em particular. (Ibidem, 2011, p. 54)

Essa dimensão teórica construída por Durkheim estará circunscrita em um aspecto importante influente no pensamento 
sociológico e educacional de seu tempo, que é o caráter laico e racional das instituições e dos sistemas educacionais. Os conceitos de sujeitos autônomos, racionais, livres e científicos pressuponham de um lado, a constituição de sistemas fundados sob a lógica definida pela sociedade organizada pelo Estado com instituições leigas e racionais, e de outro, da formação de uma elite pensante, culta e sensível que expressassem o sentido racional da humanidade.

Isso trará no olhar do pensamento educacional de Durkheim, um papel preponderante colocado no professor, à tarefa precípua na formação dos alunos. Aproxima os professores em grau e responsabilidade a dos cientistas. Segundo ele, é necessário que se forme uma elite intelectual e sensível capaz de pensar e desenvolver o espírito da humanidade, que estruture tanto o caráter da solidariedade e do altruísmo social, como desenvolva nas gerações seguintes o espírito racional e científico dos alunos. De certo modo, dá ênfase a uma educação tradicional pondo no professor o elemento formador e repassador da cultura e do conhecimento científico. Assim expressa em sua forma de ver a educação:

Não podemos nem devemos todos nos devotar ao mesmo gênero de vida; dependendo das nossas aptidões, temos funções diferentes a desempenhar, e é preciso está em harmonia com aquela que nos incumbe. Nem todos nós fomos feitos para refletir; são precisos homens de sensação e ação. Ao contrário, são precisos outros cujo trabalho seja de pensar. Ora o pensamento só pode se desenvolver ao se desprender do movimento, recolhendo-se em si mesmo e desviando o sujeito da ação exterior para que ele mergulhe por completo $\mathrm{em}$ sua mente. (ibidem, 2011, p. 44)

Embora essa citação tenha causado profundas críticas, por gerar relações dicotômicas entre o pensar e o agir, o que Durkheim efetivamente propõe é uma ação pedagógica racional e consciente, capaz de formar o sentido laico e racional da modernidade, e o professor como elemento essencial na formação desse processo, 
constituindo a partir da disciplina a liberdade estabelecida pelo estado de direito. Assim ele acrescenta,

A liberdade é a filha da autoridade bem aplicada, pois ser livre não significa fazer o que bem entender, mas sim ter o autocontrole e saber agir guiado pela razão e cumprir o seu dever. A autoridade do professor, que é apenas um aspecto de autoridade do dever da razão, deve ser empregada justamente para dotar a criança deste autocontrole. A criança deve, portanto, estar acostumada a reconhecer a autoridade na palavra do educador e a respeitar a sua autoridade. Essa é a condição para que mais tarde ela encontre em sua consciência e acate o que ela prescrever. (ibidem, 2011, p. 73)

Completando esse caráter laico e racional de sua obra pedagógica ele coloca no Estado a responsabilidade da educação: cabe a este ente e/ou a sociedade a construção laica e formativa do indivíduo. Como a sociedade é superior e coercitiva, o sistema educacional deve ser público em sua maioria, e quando privado deve ser submetido efetivamente à fiscalização e estruturação de seus organismos. Portanto ele expressa:

Uma vez que a educação é uma função essencialmente social, o Estado não pode desinteressar dela. Pelo contrário, tudo o que é educação deve ser, em certa medida, submetido à sua ação. Isto não significa, no entanto, que ela deva necessariamente monopolizar o ensino. (ibidem, 2011, p. 63)

E, acrescenta:

Porém, o fato de o Estado dever, em prol do interesse público, sua responsabilidade direta não implica que ele permaneça indiferente ao que acontece dentro das instituições. A educação que elas fornecem deve, pelo contrário, ficar submetida ao seu controle. Não é 
nem mesmo admissível que a função de educador seja desempenhada por alguém que não apresente garantias específicas que somente o Estado pode julgar. (ibidem, 2011, p. 63)

Portanto são essas reflexões que colocarão na contemporaneidade o papel de destaque da sociologia durkheimiana. Sua forma compreensiva de olhar e de interpretar as instituições traz consigo o aspecto ambíguo de seu sistema sociológico, pois de um lado possibilita a observação de aspectos institucionais positivos, e de outro, a contradição, por sua sociologia favorecer análises que justificam ações conservadoras da sociedade. É neste contexto que influenciará o olhar na educação nos dias atuais.

\section{Considerações finais}

À guisa de conclusão, o artigo caminha na ideia de ao invés de se fazer considerações efetivas sobre o arcabouço teórico do autor acima exposto - relacionado à educação, de vislumbrarmos a partir dos conceitos de evolução, equilíbrio, integração e estabilidade a influência de sua teoria sobre as abordagens modernas sociológicas que possibilitam na atualidade um olhar sobre os sistemas educacionais.

Assim, poderíamos pensar tomando como referência Carlos Alberto Torres (1997), três aspectos fundamentais de sua teoria que possibilitaram sua influência nas teorias modernas do pensamento sociológico e educacional. O primeiro deles é a sua forma evolucionista do pensamento introduzido pelo seu conceito de história, no qual incorpora a ideia de contexto fundamentando, a partir das mudanças econômicas e culturais, a evolução sistêmica da educação. Aspecto apresentado em sua obra "Sobre a Evolução Pedagógica" no qual a passagem do espírito religioso presente na educação para uma dinâmica laica e pública, deveu-se às mudanças sociais ocorridas da idade média cristã para o mundo racional moderno. 


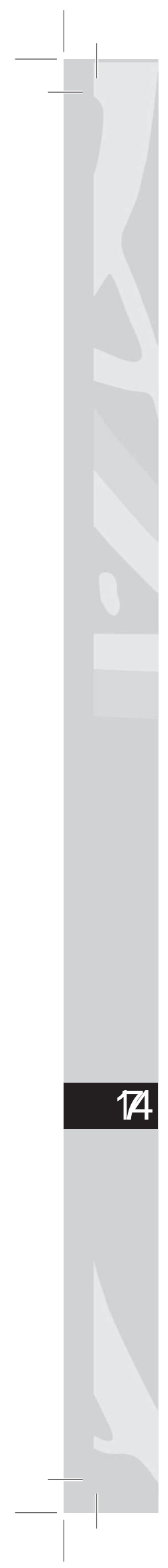

O segundo aspecto circunscreve na concepção apresentada na obra "Educação e Sociologia" em que demonstra uma efetiva ênfase no caráter integrador e funcional da educação, o que se justifica que a dinâmica evolucionista dos sistemas educacionais se organiza e se estrutura por uma forte integração cultural das gerações passadas com as gerações futuras, e do mesmo modo, são intensificadas com a divisão técnica e científica da divisão social do trabalho potencializada pelas especializações presentes nas sociedades urbanas e industriais.

E por último, subscrevendo essa concepção colocada acima, perpassa na influência dos conceitos de solidariedade mecânica e orgânica que favorece na sociedade moderna a funcionalidade das regras do estado de direito, em que exigiria a construção de uma nova pedagogia pressuposta da necessidade de uma maior individuação na sociedade moderna, o que levaria da passagem de uma educação espiritual a expressão da transformação a uma pedagogia racional e, por consequência, a reorganização sistêmica da escola. O que na linguagem de Morrow \& Torres (1997) levaria a uma concepção racional e secular do individualismo e, do mesmo modo, à mudança inevitável por maior sede de justiça, laica e racional; transformando, portanto, o sentido da educação.

Esses três elementos potencializarão a influência durkheimiana nas teorias, desde o final do século XIX e início do XX na antropologia funcionalista Levi Strauss, Malinovski e outros, a passagem progressista de Bourdieu e sua teoria da Reprodução, aos conceitos de integração e mudança de Merton. Além da análise das estruturas sistêmicas de Parsons influenciado por uma concepção mais conservadora do pensamento de Durkheim. Demonstrando, assim o alcance da teoria do mesmo em seu caráter progressista da modernidade social democrata, ao liberalismo sistêmico da sociedade capitalista e do estado moderno presente nas teorias da reprodução social e de investigação sistêmica da educação na contemporaneidade. 


\section{REFERÊNCIAS}

BACON, Francis. Novum Organum. São Paulo: Nova Cultural, 1980.

COMTE, Auguste. Discurso Sobre o Espírito Positivo. São Paulo: Ciro Moranza,1995.

DURKHEIM, Emile. As Regras do Método Sociológico. 17 ed. São Paulo: Companhia Editora Nacional, 2002. 1995.

A Evolução Pedagógica. Porto Alegre: Artes Médicas,

Educação e Sociedade. Petrópolis: Vozes, 2011.

KANT, Immanuel. Textos Seletos. Petrópolis: Vozes, 1985.

Obras Pedagógicas. São Paulo: UNESP, 1990.

MORROW, Raymond A. \& TORRES, Carlos A. Teoria Social e Educação: uma crítica das teorias da reprodução social e cultural. Porto: Edições Afrontamento, 1997. 